\title{
GENETIC POLYMORPHISMS IN STAT4, IRF5, HLA, AND BLK AND THEIR CONTRIBUTION TO SYSTEMIC LUPUS ERYTHEMATOSUS IN BRAZILIAN PATIENTS
}

Anna Paula Mota Duque Sousa ${ }^{1,2}$, Giselle Calasans de Souza Costa ${ }^{2,3}$, Gustavo Nunes de Oliveira Costa ${ }^{2}$, Lúcio Macedo Barbosa ${ }^{3}$, Maria Fernanda Rios Grassi ${ }^{3}$, Maria Eduarda Haerdy Monteiro ${ }^{2}$, Mitermayer Galvão dos Reis ${ }^{3}$, Maurício Lima Barreto ${ }^{3}$, Ana Luisa Pedreira ${ }^{1,2}$, Daniel Sá Ribeiro ${ }^{1}$, Carolina Freitas Lins ${ }^{1}$, Verena Galvão ${ }^{1}$, Viviane Machicado ${ }^{1,2}$, Emanuela Pimenta da Fonseca ${ }^{1}$, Mittermayer Barreto Santiago ${ }^{1,2,4, *}$

1.Escola Bahiana de Medicina e Saúde Pública - Salvador, BA, Brazil. 2.Universidade Federal da Bahia, Salvador (BA), Brazil. 3.Fundação Oswaldo Cruz, Salvador (BA), Brazil. 4.Serviços Especializados em Reumatologia da Bahia, Salvador (BA), Brazil.

*Corresponding author: mitter.santiago@serdabahia.com.br_

\section{BACKGROUND}

Polymorphisms in genes such as STAT4, IRF5, HLA, and BLK induce autoimmunity by induction of interferon production and activation of $T$ and $B$ cells. They have been associated with systemic lupus erythematosus (SLE) in several populations. The present study aimed to evaluate their association with SLE, along with its clinical and laboratory features, in Brazilian patients. The study also reviewed the role of these genes and some polymorphisms in the disease.

\section{MATERIALS AND METHODS}

Systemic lupus erythematosus patients from rheumatology centers in Bahia, Brazil, were included in the study. Individuals without SLE were included as a control group. All participants were genotyped for rs7574865, rs9271100, rs10488631, and rs13277113 polymorphisms in STAT4, HLA, IRF5, and BLK genes, respectively, by real-time PCR. The allelic and genotypic frequencies were correlated with the presence of SLE and clinical and laboratory findings. Results were adjusted for sex and skin color in multivariate analysis.

\section{RESULTS}

A total of 106 patients with SLE and 614 healthy controls were in the study. Higher frequencies of both T allele of rs7574865 in the STAT4 and C allele of rs10488631 in IRF5 were found in SLE patients as compared to controls, but multivariate analysis demonstrated a statistical significance in only STAT4 gene. The polymorphisms evaluated and SLE manifestations were found to be not associated.

\section{CONCLUSION}

The rs7574865 polymorphism in the STAT4 gene is associated with SLE in patients from Brazil. Further studies are required to understand the performance of genetic factors in populations considering their ethnic differences and also clinical applicability and therapeutic perspectives. 